\title{
Monosodium urate crystals induce oxidative stress in human synoviocytes
}

\author{
Yessica Zamudio-Cuevas ${ }^{1,2}$, Karina Martínez-Flores', Javier Fernández-Torres ${ }^{1,3}$, Yahir A. Loissell-Baltazar ${ }^{2}$, \\ Daniel Medina-Luna', Ambar López-Macay', Javier Camacho-Galindo' , Cristina Hernández-Díaz', \\ Mónica G. Santamaría-Olmedo ${ }^{1}$, Edgar Oliver López-Villegas ${ }^{4}$, Francesca Oliviero ${ }^{5}$, Anna Scanu ${ }^{5}$, \\ Jorge Francisco Cerna-Cortés ${ }^{2}$, Marwin Gutierrez ${ }^{1}$, Carlos Pineda ${ }^{1}$ and Alberto López-Reyes ${ }^{1 *}$
}

\begin{abstract}
Background: Gout is the most common inflammatory arthropathy of metabolic origin and it is characterized by intense inflammation, the underlying mechanisms of which are unknown. The aim of this study was to evaluate the oxidative stress in human fibroblast-like synoviocytes (FLS) exposed to monosodium urate (MSU) crystals, which trigger an inflammatory process.

Methods: Human FLS isolated from synovial tissue explants were stimulated with MSU crystals $(75 \mu \mathrm{g} / \mathrm{mL})$ for $24 \mathrm{~h}$. Cellular viability was evaluated by crystal violet staining, apoptosis was assessed using Annexin $\mathrm{V}$, and the cellular content of reactive oxygen species (ROS) and nitrogen species (RNS) $\left(\mathrm{O}_{2}^{-}, \mathrm{H}_{2} \mathrm{O}_{2}, \mathrm{NO}\right)$ was assessed with image-based cytometry and fluorometric methods. In order to determine protein oxidation levels, protein carbonyls were detected through oxyblot analysis, and cell ultrastructural changes were assessed by transmission electron microscopy.

Results: The viability of FLS exposed to MSU crystals decreased by $30 \%(P<0.05)$, while apoptosis increased by $42 \%$ $(P=0.01)$. FLS stimulated with MSU crystals exhibited a 2.1-fold increase in $\mathrm{H}_{2} \mathrm{O}_{2}$ content and a 1.5-fold increase in $\mathrm{O}_{2}^{-}$ and NO levels. Oxyblots revealed that the spots obtained from FLS protein lysates exposed to MSU crystals exhibited protein carbonyl immunoreactivity, which reflects the presence of oxidatively modified proteins. Concomitantly, MSU crystals triggered the induction of changes in the morphostructure of FLS, such as the thickening and discontinuity of the endoplasmic reticulum, and the formation of vacuoles and misfolded glycoproteins.
\end{abstract}

Conclusions: Our results prove that MSU crystals induce the release of ROS and RNS in FLS, subsequently oxidizing proteins and altering the cellular oxidative state of the endoplasmic reticulum, which results in FLS apoptosis.

Keywords: Monosodium urate crystals, Gout, Oxidative stress, Synoviocytes

\section{Background}

Gout is a uric acid (UA) metabolic disorder that promotes the formation and deposition of monosodium urate (MSU) crystals inside joints and periarticular soft tissues as a result of hyperuricemia. It is the most common inflammatory arthropathy in young men, and its prevalence is underestimated due to the long asymptomatic phase of the disease [1]. The global burden of gout is substantial and has increased in many parts of the world over the past

\footnotetext{
* Correspondence: allorey@yahoo.com

'Laboratorio de Líquido Sinovial, Instituto Nacional de Rehabilitación "Luis Guillermo Ibarra Ibarra", Calzada México-Xochimilco 289, Tlalpan, 14389 Mexico City, Mexico

Full list of author information is available at the end of the article
}

50 years [2]. Gout causes monocytic inflammatory cells to phagocytose MSU crystals. This induces the release of pro-inflammatory cytokines such as IL-8, IL-6, CCL2, interferon (IFN)- $\gamma$, and IL- $1 \beta$ by assembling and activating the NOD-like receptor pyrin containing 3 (NLRP3) inflammasome $[3,4]$.

The deleterious effects of urate are primarily attributed to its ability to trigger the formation of reactive oxygen species (ROS) and activate NLRP3. However, these mechanisms have not yet been elucidated $[5,6]$. The activation of NADPH oxidase, xanthine oxidase, and nitric oxide synthase enzymes generates hydrogen peroxide $\left(\mathrm{H}_{2} \mathrm{O}_{2}\right)$, superoxide anion $\left(\mathrm{O}_{2}^{-}\right)$and nitric oxide $(\mathrm{NO})$, respectively. The interaction of these last two molecules promotes the 
generation of peroxynitrite $\left(\mathrm{ONOO}^{-}\right)$, which in turn increases apoptosis, the degradation of connective tissues, and joint damage $[7,8]$. However, due to the complex interactions that take place within joints among various cell types, including neutrophils, macrophages, mast cells, endothelial cells and synovial fibroblasts, it is possible for synovial fibroblasts to play a role in modulating the inflammatory response to MSU crystals in patients with gout $[9,10]$.

Previous studies have reported that endogenous ROS are overproduced during acute gout attacks, suggesting that oxidative stress (OS) contributes to acute gout attacks and to the painful and inflammatory responses that MSU crystals induce by currently unknown mechanisms [11]. The aim of this study was to evaluate the prooxidizing effect of MSU crystals in an in vitro model of crystal-induced inflammation. We focused on ROS and RNS associated with the generation of OS induced by MSU crystals in human-derived synovial membrane (SM) cells. We found that MSU crystals trigger an oxidative response and oxidize proteins, highlighting a possible mechanism underlying gout pathogenesis. The results shown here help explain how MSU crystals combined with ROS react with proteins of synoviocytes, increasing our understanding of the role of OS in the development of gout.

\section{Methods}

This study was approved by the Research Committee of the Instituto Nacional de Rehabilitacion (Ref.02/13) of Mexico and was carried out according to the principles of the Helsinki declaration. Written informed consent was obtained from all patients.

\section{MSU preparation}

MSU crystals were synthesized by uric acid (UA) crystallization according to the method described by Denko and Whitehouse [12] and modified by Scanu et al. [10]. MSU crystals were characterized by polarized light microscopy and scanning electron microscopy (SEM) based on the crystallographic characteristics birefringence, size, and morphology [13], and were sterilized at $180{ }^{\circ} \mathrm{C}$ for $2 \mathrm{~h}$. The absence of microbial contaminants was confirmed by culturing for microorganisms, and the crystals were determined to be bacterial endotoxin-free by Limulus amebocyte cell-lysate assay (Sigma-Aldrich).

\section{Isolation and cell culture of fibro-synoviocytes}

A primary culture of synoviocytes was obtained via mechanic-enzymatic breakdown of SM collected from patients with osteoarthritis (OA) $(n=5)$ during knee joint replacement. Synoviocytes were isolated from tissue explants following digestion with collagenase type IA (1 $\mathrm{mg} / \mathrm{mL}$ ) (Gibco, Life Technologies) for $2 \mathrm{~h}$ with mixing at $37{ }^{\circ} \mathrm{C}$. Cells were seeded in T25 flasks at a density of 250,000/flask until confluence. The cells were cultured in DMEM-F12 supplemented with $10 \%$ fetal bovine serum and $1 \%$ penicillin-streptomycin (Gibco, Life Technologies), and they were incubated in a controlled $\mathrm{CO}_{2}$ atmosphere at a regulated temperature. At confluence, cells were harvested (TrypLE Express, Gibco, Life Technologies) and seeded into new flasks that kept synoviocytes from different patients separated. For the experiments, cells were used at the third or fourth passage.

\section{Phenotyping of fibroblast-like synoviocytes analysis Characterization by $q R T-P C R$}

Upon the third passage, fibroblast-like synoviocytes (FLS) phenotype was determined by assessing the expression of the uridine diphosphate glucose dehydrogenase gene $(U G D H)$, and $C D 14$ gene was used for macrophagelike synoviocytes by qRT-PCR. Total RNA from each patient was extracted by the Trizol method [14]. The qRTPCR technique was performed by amplifying primers (Additional file 1) in a Rotor-Gene Q thermocycler (Qiagen), according to the commercial kit $\mathrm{RT}^{2}$ First Strand Kit from Qiagen. The results were normalized to the housekeeping GAPDH gene and relative quantification was performed through REST-09 software (Relative Expression Tool software 2009). After amplification, a melting assay was performed to confirm the specific size of the products of each gene.

\section{Characterization by immunofluorescence and western blot}

Expression of prolyl-4-hydroxylase (PDH4) was evaluated by immunofluorescence assay (IFA) and Western blot (WB). For IFA, cells were seeded into fixed and permeated chamber-slides. Subsequently, primary antibody PDH4 (ab108980, Abcam) was incubated. Afterwards, secondary antibody (ab175471 Alexa Fluor ${ }^{\oplus}$ 568, Abcam) was incubated. Finally, images were captured with an Ism 5 beta Carl Zeiss microscope.

Total protein was obtained from the culture of sinoviocytes. Analysis of the protein content was performed by WB according to Serratos et al. [15] Normalization was performed with Beta-actin antibody from Sigma (A3854). Blots were revealed using Immobilon Western Chemiluminescent HRP Substrate (Millipore Corporation, USA). The blots were scanned with an Amersham Imager 600 RGB (GE) and densitometry was analyzed using ImageQuant TL 8.1 software.

\section{Characterization by flow cytometry}

To evaluate surface markers associated with fibroblasts and macrophage, a flow cytometry (FC) assay was performed according to Landa-Solís $C$ et al. [16] Cells were marked with monoclonal antibodies PE-conjugated 
CD166 and PE-conjugated CD14 from BD PharMigenTM (San Diego, CA, USA). Data were collected through a BD FACSCalibur flow cytometer and analyzed with CellQuestTM PRO software (Becton-Dickinson).

\section{Cell stimulation, viability, and apoptosis}

FLS were treated for $24 \mathrm{~h}$ with MSU crystals at 0, 60, 75, 80 , and $100 \mu \mathrm{g} / \mathrm{mL}$. Cell viability was assessed by the crystal violet method [17] after MSU crystal cell stimulation. Based on these results, only one concentration was used for all subsequent tests. FLS apoptosis was assessed by $\mathrm{FC}$ detection of annexin $\mathrm{V}$ using a commercial kit (Annexin V Alexa Fluor 488 from Molecular Probes). Treatment with $100 \mu \mathrm{M} \mathrm{H}_{2} \mathrm{O}_{2}$ for 30 minutes was used as positive control for oxidation because an increase in $\mathrm{H}_{2} \mathrm{O}_{2}$ formation is associated with inflammation and fast OS induction in cells [18]. Unstimulated cells were used as negative control.

\section{Assessment of oxidative stress}

Oxidative stress was evaluated by determining intracellular $\mathrm{O}_{2}^{-}$through oxidation of dihydroethidium (DHE, hydroethidine) at a $606 \mathrm{~nm}$ emission wavelength, according to the manufacturer's instructions, using a Tali Image-based Cytometer (Life Technologies). $\mathrm{H}_{2} \mathrm{O}_{2}$ was detected by oxidation of 5-, 6- carboxy-2', 2', 7'diclorofluorescein diacetate (carboxy-H2DCFDA) (ImageiT LIVE Green Reactive Oxygen Species Detection) using a fluorescence reader (BD, Beckman Coulter, AXT-800) at $530 \mathrm{~nm}$. NO was quantified by benzotriazole formation with a commercial kit, DAF-FM (4-amino-5-methylamino2,7-difluorofluorescein diacetate, Molecular Probes) at $515 \mathrm{~nm}$ in Tali Image-based Cytometer. Data analysis was performed based on fluorescence intensities.

\section{Protein oxidation}

After derivatization using 2, 4-dinitrophenylhydrazine $(\mathrm{DNPH})$, the protein oxidation products were identified by scanning carbonyl groups with the OxyblotTM Protein Oxidation Detection Kit (Millipore Inc.) according to the manufacturer's instructions. Image detection was performed with two methods: a conventional chemiluminescent detection and a fluorescence method using ECL Plex goat-alfa-rabbit IgG-Cy5 (GE, Healthcare), a $630 \mathrm{~nm}$ excitation filter and a $670 \mathrm{~nm}$ emission filter. The images were scanned with Amersham Imager 600 RGB (GE, Healthcare), and analyzed using ImageQuant TL 8.1 software.

\section{Morphostructural characterization by transmission electron microscopy}

The FLS were fixed with $2.5 \%$ glutaraldehyde, treated with $1 \%$ osmium tetroxide, and dehydrated with alcohol and propylene oxide. The samples were embedded in an epoxy resin and polymerized at $60{ }^{\circ} \mathrm{C}$ for $24 \mathrm{~h}$. Sections were cut 80-90 nm thick, and stained with $4 \%$ uranyl acetate and lead citrate. The cells were then analyzed under a transmission electron microscope (TEM; Philips, model Tecnai 10) equipped with a Mega View II digital camera. A voltage of $80 \mathrm{kV}$ was employed.

\section{Statistical analysis}

Each experiment was performed at least three times with the sample from each patient in independent experiments. Mean values were statistically analyzed with GraphPad Prism v. 6.0 using variance analysis, followed by the one-way post hoc Dunnett test. $P<0.05$ was considered statistically significant.

\section{Results}

\section{MSU crystallization}

As evidenced by polarized light microscopy and SEM, chemically synthesized MSU crystals exhibited a characteristic needle-shaped negative birefringence, a 5-40 $\mu \mathrm{m}$ range size, and triclinic structure [19]. In addition, two blinded experts reported similar morphological characteristics in synthetic MSU crystals and those obtained from the synovial fluid of patients during an acute gouty attack, and they were unable to differentiate between the two types of crystals (data not shown) (see Additional file 2).

\section{FLS characterization}

FLS isolated during SM biopsies expressed the PDH4 protein, UDGH gene and CD166 membrane receptor, as assessed by WB, IFA, qRT-PCR and FC, respectively (data not shown) (see Additional files 3, 4, and 5).

\section{Assessment of cell viability and apoptosis}

Cell cultures exposed to MSU crystals at a concentration of $75 \mu \mathrm{g} / \mathrm{mL}$ maintained a viability of $77 \% \pm 0.50$, while a concentration of $100 \mu \mathrm{g} / \mathrm{mL}$ resulted in a viability of $54.82 \% \pm 0.46$ compared to unstimulated FLS $(P \leq 0.05)$ (Fig. 1a). FLS exposed to $75 \mu \mathrm{g} / \mathrm{mL}$ MSU had invagination of crystals in the cytoplasm and cellular stress (Fig. 1b).

Adding MSU crystals at $75 \mu \mathrm{g} / \mathrm{mL}$ or $\mathrm{H}_{2} \mathrm{O}_{2}$ at $100 \mu \mathrm{M}$ induced apoptosis in 42 and $45 \%$ of cells, respectively, compared to $21 \%$ cell apoptosis observed in unstimulated cultures. This increment was significant $(P \leq 0.05)$ (Fig. 1c). Based on these results, we used a concentration of $75 \mu \mathrm{g} / \mathrm{mL}$ MSU for all subsequent experiments.

\section{Evaluation of oxidative stress}

MSU crystals induced a 2.5-fold increase in intracellular production of $\mathrm{H}_{2} \mathrm{O}_{2}$ in comparison to untreated FLS $(P<0.05)$, and a 2.1 -fold increase compared to a positive control (Fig. 2a-c and g). Similarly, stimulating FLS with crystals for $24 \mathrm{~h}$ or with $\mathrm{H}_{2} \mathrm{O}_{2}$ for 30 minutes yielded 


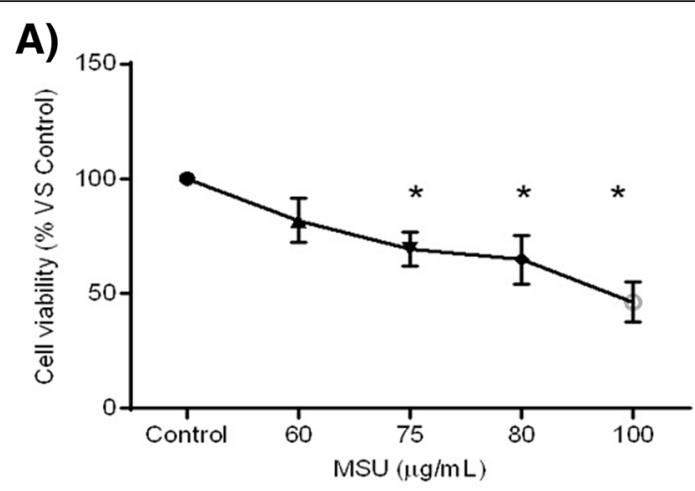

B)

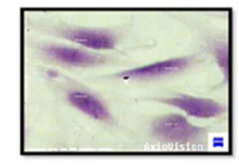

Control

C)

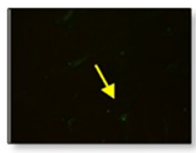

Control

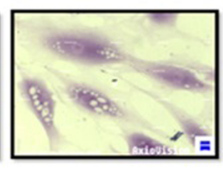

$60 \mu \mathrm{g} / \mathrm{mL}$

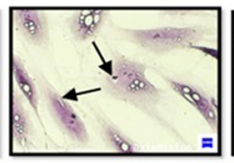

$75 \mu \mathrm{g} / \mathrm{mL}$

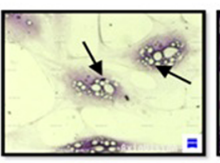

$80 \mu \mathrm{g} / \mathrm{mL}$

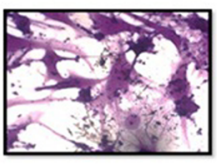

$100 \mu \mathrm{g} / \mathrm{mL}$

Fig. 1 Cellular response to the presence of monosodium urate (MSU) crystals. a Cell viability after a $24 \mathrm{~h}$ treatment. b Cell morphological changes after MSU crystal exposure. The arrows indicate the intracellular vacuoles of MSU crystals. c Apoptosis is revealed by Annexin $V$ detection (yellow arrows) in synoviocytes exposed to MSU crystals and $\mathrm{H}_{2} \mathrm{O}_{2}(100 \mu \mathrm{M})$. Additionally, columns show quantification of the apoptotic cells by flow cytometry. Values are expressed as the mean \pm standard deviation ${ }^{*} P<0.05$ vs control

1.5-fold and 1.8-fold increases in $\mathrm{O}_{2}^{-}$, respectively, compared to untreated FLS (Fig. 2d-f and g). Finally, only a 1.5-fold increase in NO was observed in FLS upon exposure to MSU crystals (Fig. 3).

\section{Analysis of oxidized proteins}

FLS exposed to MSU crystals had a protein oxidation pattern similar to the one observed in $\mathrm{H}_{2} \mathrm{O}_{2}$-treated cells, in comparison to unstimulated FLS (Fig. 4a, b).

\section{Ultrastructural analysis}

Untreated FLS were analyzed under transmission electron microscopy (TEM). The cells exhibited irregular nuclei containing loose chromatin; the mitochondria, rough endoplasmic reticulum (ER) and vacuoles were distributed homogeneously throughout the cytoplasm; and cytoplasmic prolongations were observed (Fig. 5a, b).

In addition to the presence of intracellular crystals, MSU crystal-stimulated FLS had an increased number of vacuoles and a reduction of ER (Fig. 5c). Furthermore, aggregates of misfolded glycoproteins (MP) were evident in the lumen (Fig. 5d). These aggregates were also observed to a lesser extent in the FLS incubated with $\mathrm{H}_{2} \mathrm{O}_{2}$, although few cytoplasmic prolongations were present (Fig. 5e, f).

\section{Discussion}

The current study revealed that MSU crystals are able to decrease cell viability through apoptosis induction in FLS. Although the definitive mechanism for MSUinduced apoptosis has not been established, it has been demonstrated that MSU crystals exert different apoptotic effects depending on the cell type interacting with the crystals. While some studies have reported that MSU crystals inhibit neutrophil apoptosis [20], others have shown that they do not induce any change in the percentage of apoptosis for osteoblast-like cells [21]. Recently, MSU crystals have been shown to promote renal 

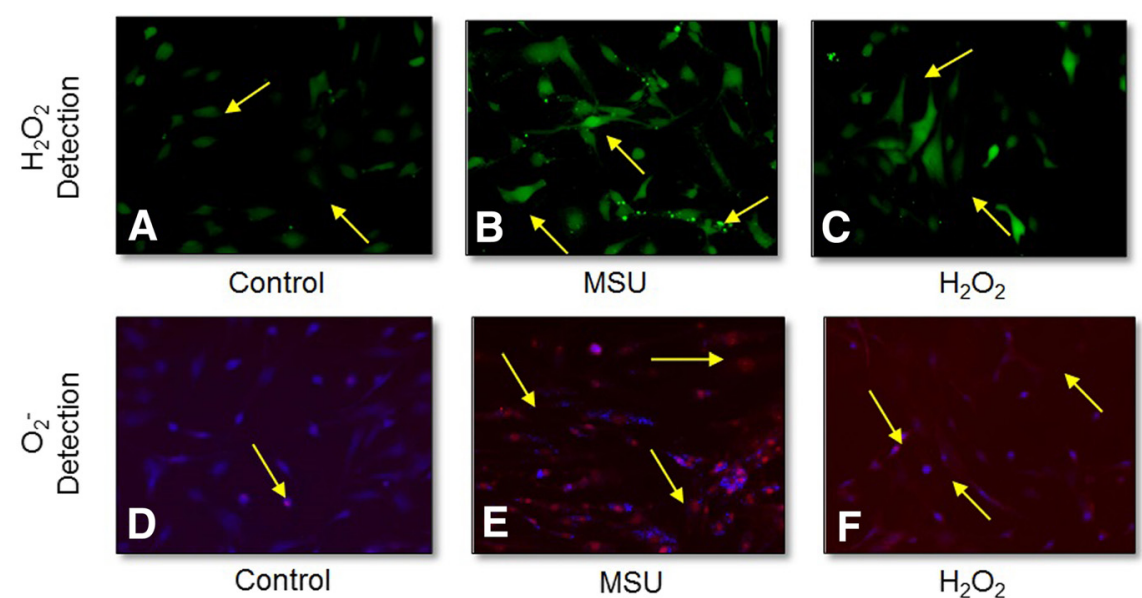

MSU

$\mathrm{H}_{2} \mathrm{O}_{2}$

$\mathbf{G}$
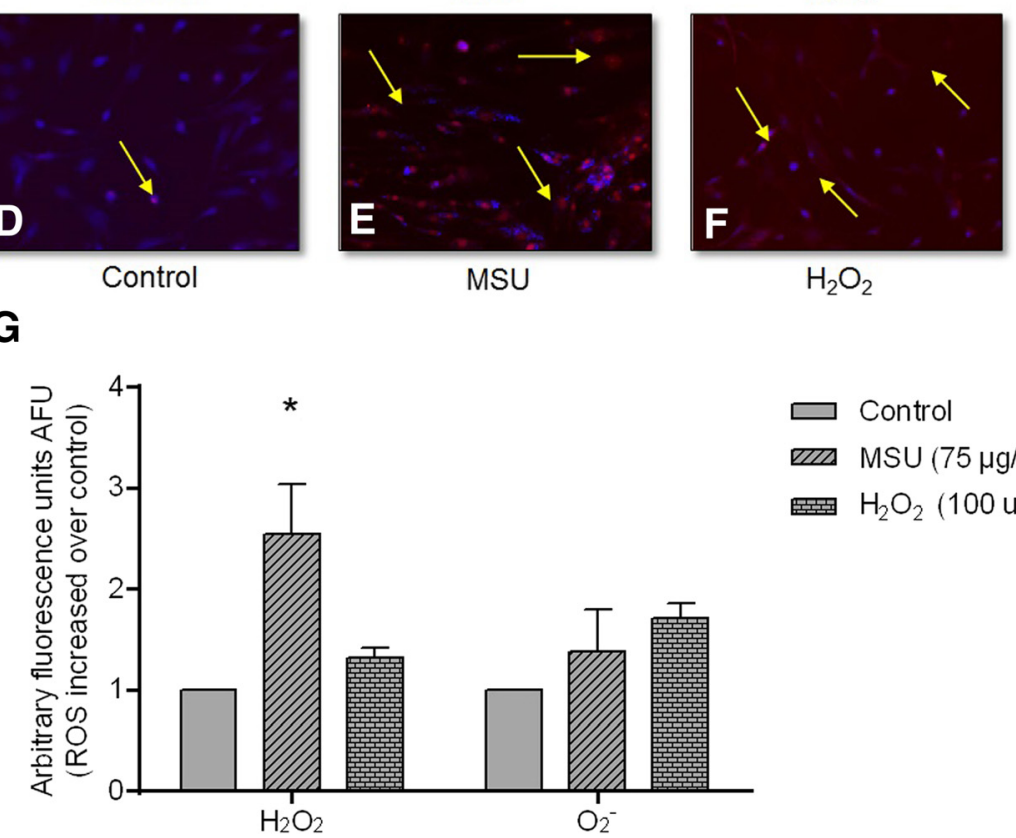

Fig. 2 Monosodium urate (MSU) crystals increase reactive oxygen species (ROS) in synoviocytes. Arrows indicate intracellular $\mathrm{H}_{2} \mathrm{O}_{2}$ formation, which is revealed by DCFH oxidation (green fluorescence) in untreated fibroblast-like synoviocytes (FLS) (a); FLS treated with MSU crystals at $24 \mathrm{~h}$ (b), and FLS treated with $\mathrm{H}_{2} \mathrm{O}_{2}$ at 30 minutes (c). Arrows indicate $\mathrm{O}_{2}^{-}$intracellular production by oxidation of dihydroethidium (DHE) (red fluorescence) in untreated FLS (d); FLS treated with MSU crystals (e), and FLS treated with $\mathrm{H}_{2} \mathrm{O}_{2}$ (f). Bars show quantification of DCFH and DHE fluorescence: data are reported as units of arbitrary fluorescence (UAF) (g). Values are expressed as the mean \pm standard deviation; ${ }^{*} P<0.05$ vs control

cell apoptosis through a mechanism involving ROS generation [22]. However, no data were available on their influence on FLS. According to one report, apoptosis is induced in chondrocytes isolated from patients with RA following stimulation with MSU crystals [23]. The association of this apoptotic state with the loss of cartilage repair and regeneration capacity could highlight a link between FLS apoptosis and the tissue damage observed in gouty patients. Moreover, the relationship between the increment of ROS and NO and the loss of FLS viability caused by MSU crystals is consistent with published findings [24-26].

In addition, we established that crystal-exposed FLS produced $\mathrm{H}_{2} \mathrm{O}_{2}, \mathrm{O}_{2}^{-}$and, to a lesser extent, $\mathrm{NO}$, promoting a state of cellular oxidation. One mechanism involved in ROS production is the NADPH oxidase system in THP-1 cells stimulated with MSU crystals [27]. This mechanism of ROS generation has also been shown in FLS from patients with OA and RA that were exposed to TNF- $\alpha$ and IL-1 $\beta$, exhibiting a heightened state of cellular oxidation [28]. Our experiments proved, via an increase in ROS/RNS, that MSU crystals activated an oxidative state in FLS. The increase in $\mathrm{H}_{2} \mathrm{O}_{2}$ observed in FLS exposed to MSU crystals for $24 \mathrm{~h}$ is similar to that reported for FLS stimulated with advanced oxidation proteins products; a threefold to eightfold increase in $\mathrm{H}_{2} \mathrm{O}_{2}$ was observed compared to unstimulated control cells [29]. This suggests that MSU crystal-mediated ROS overproduction in FLS is involved in the disturbance of homeostasis within the joint microenvironment, which can damage all cellular components, including DNA, lipids and proteins [30]. However, proteins are possibly the most immediate vehicle for inflicting oxidative damage on cells because they are often catalysts. Therefore, we assessed the influence of ROS in oxidized protein content of FLS affected by MSU crystals.

The impact of ROS on the proteins of FLS with MSU crystals was clearly seen on images because there were more spots and with higher intensities than in control cells, indicating increased carbonyl content. While there 


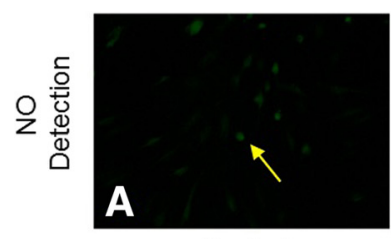

Control

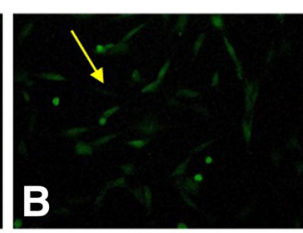

MSU

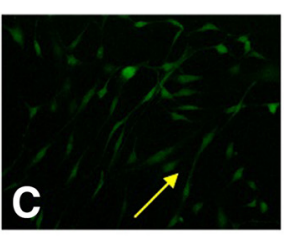

$\mathrm{H}_{2} \mathrm{O}_{2}$

D

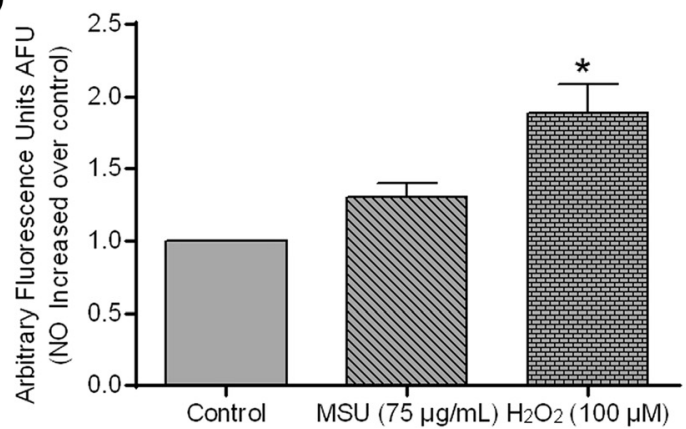

$\square$ Control

$\operatorname{MSU}(75 \mu \mathrm{g} / \mathrm{mL})$

$\mathrm{H}_{2} \mathrm{O}_{2}(100 \mu \mathrm{M})$

Control MSU $(75 \mu \mathrm{g} / \mathrm{mL}) \mathrm{H}_{2} \mathrm{O}_{2}(100 \mu \mathrm{M})$

Fig. 3 Nitric oxide (NO) production in synoviocytes. a Detection of NO in untreated fibroblast-like synoviocytes (FLS). b FLS treated with monosodium urate (MSU) crystals. c FLS treated with $\mathrm{H}_{2} \mathrm{O}_{2}$. Arrows indicate fluorescence produced by intracellular NO. d Bars show NO quantification by Tali image-based cytometer. Values are expressed as the mean \pm standard deviation; ${ }^{*} P<0.05$ vs control

are no reports that can be directly compared to our data, accumulation of protein carbonyls [31] has been observed in some rheumatic diseases (including RA and psoriasis), but it is known that exposure of proteins to ROS leads to denaturalization, loss of function, crosslinking, aggregation, and fragmentation. Under these conditions, it is suggested that accumulation of some compounds in the joint, like glycosaminoglycans and hyaluronic acid, cause damage by reducing joint viscosity [32]. However, there are no studies of the underlying mechanism. We suspected that the increase in OS might be contributing to synovial cell damage altering the functional and structural integrity. Therefore, we visualized OS-induced ultrastructural changes triggered by MSU-crystals in gout. In our model, we observed an increase in rough ER and in the presence of MP aggregates due to cellular stress in the FLS. These findings are similar to those described for synoviocytes exposed to an adjuvant used for treating arthritis (i.e., a reduction of the Golgi apparatus, mitochondria and ER [33]), and to the ones describing the appearance of vacuoles in FLS cytoplasm due to the internalization of particles. In addition, intracellular lysosomes and other cytoplasmatic formations were found [34], and these morphological changes suggest the induction of autophagy in the cells [35].
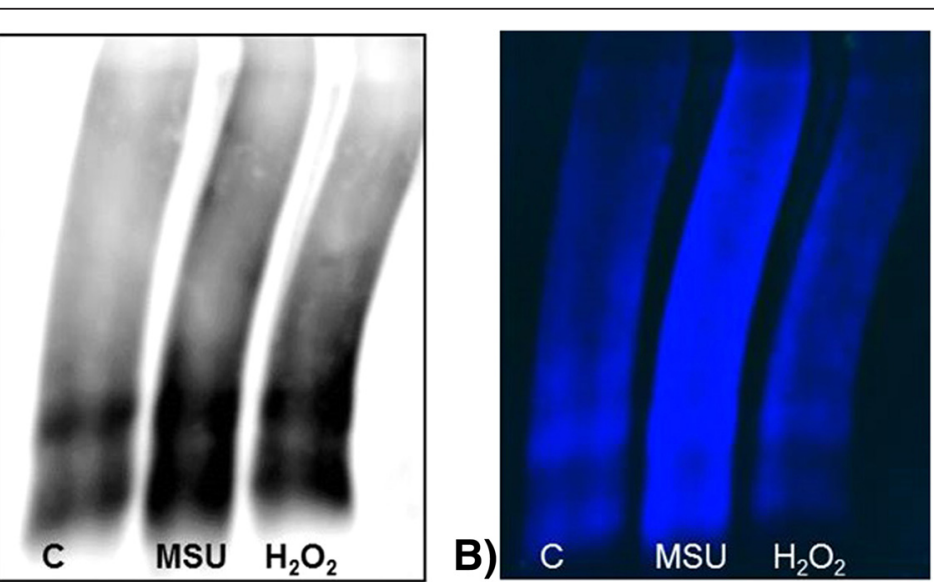

Fig. 4 Oxidized proteins assay. a Representative oxyblot of fibroblast-like synoviocytes (FLS) proteins from control group (line 1); FLS proteins exposed to monosodium urate (MSU) crystals (line 2); and FLS proteins from the positive control sample (line 3). b Oxidation scan with fluorescence detector. Results are representative of independent experiments with cells from different patients 

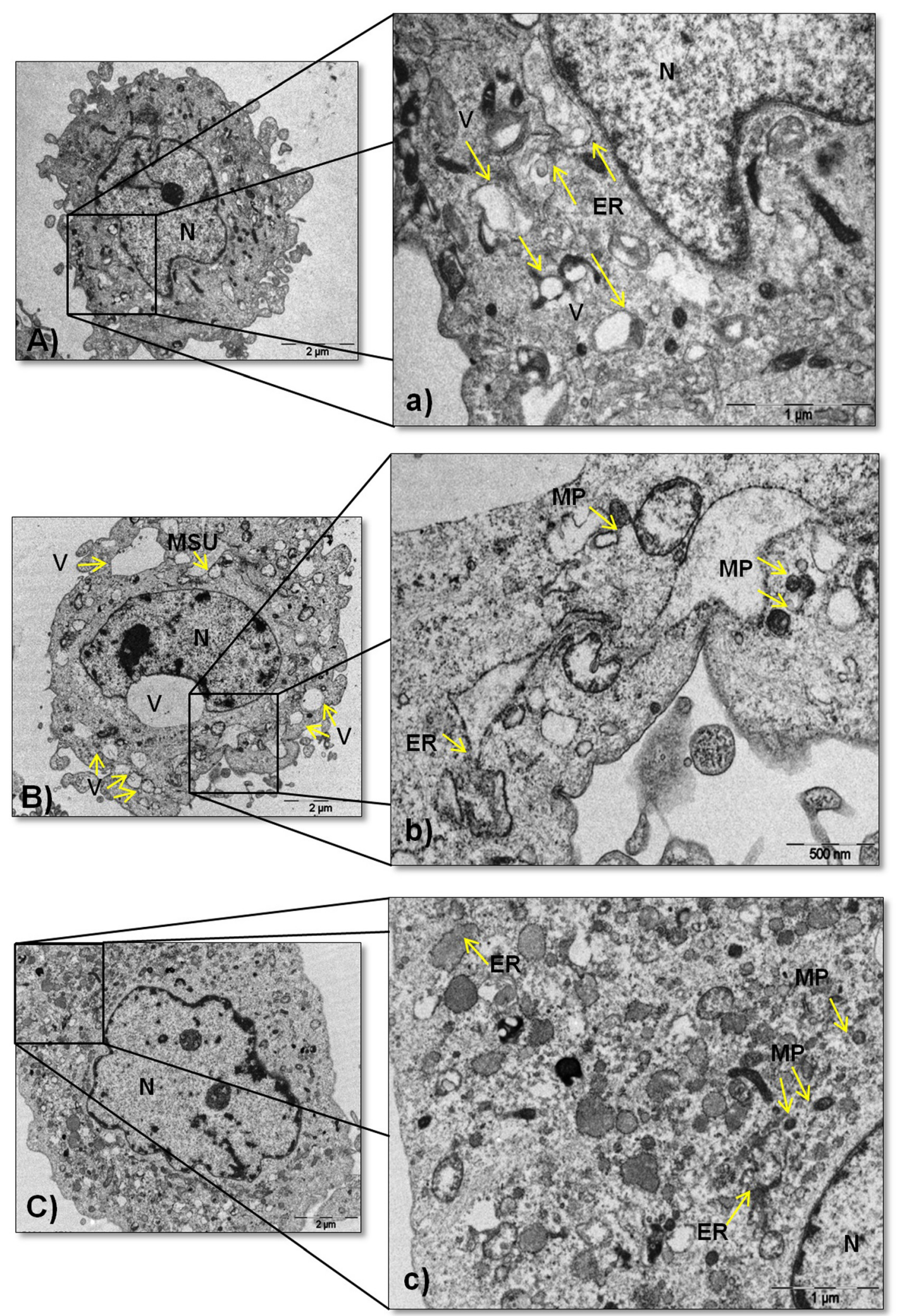

Fig. 5 (See legend on next page.) 
(See figure on previous page.)

Fig. 5 Ultrastructural changes in synoviocytes. A Ultrastructure of an untreated fibroblast-like synoviocytes (FLS). a Magnified view of the section is indicated by a black box showing the nucleus $(N)$, endoplasmic reticulum $(E R)$ and vacuoles ( $V$ highlighted with arrows. B FLS treated with monosodium urate (MSU) crystals at $75 \mu \mathrm{g} / \mathrm{mL}$ exhibiting N, swollen vesicular structures of different sizes, and MSU crystal cavity. b A high-magnification image showing misfolded proteins (MP) aggregates and ER indicated with arrows. C FLS treated with $\mathrm{H}_{2} \mathrm{O}_{2}$ at $100 \mu \mathrm{M}$ showing N. c A magnified view of the section is indicated by a black box showing MP aggregates, ER and N. Results are representative of one of five separate experiments with FLS from different patients

An important unanswered question is the mechanism responsible for activating OS in response to MSU crystals in FLS. We can speculate that this effect might be related to the mechanism involved in the overproduction of ROS and the decrease of anti-oxidative enzymes caused by lead-induced OS [36]. However, the molecular pathways involved in MSU-induced OS in FLS are not yet completely understood. Inhibition studies of these pathways may be helpful to understand the signaling network behind MSU crystals.

\section{Conclusions}

In conclusion, this study reveals that the exposure of FLS to MSU crystals promotes an oxidizing state, which may induce an apoptotic state and decrease cell viability and synovial integrity. Nevertheless, further studies are needed to achieve a better understanding of the signal transduction pathways by which MSU crystals enhance the damage generated in FLS, and to elucidate the molecular mechanism of OS in gout. This study confirms the oxidative role of MSU crystals in FLS, which could contribute to the inflammation and pain experienced during an acute gout attack. This model of OS in FLS is important for determining the role of antioxidants involved in local and systemic damage to the joint in the development of novel therapeutic targets to block OS.

\section{Additional files}

Additional file 1: Table S1. Primers used for qRT-PCR gene analysis. (DOCX $14 \mathrm{~kb}$ )

Additional file 2: Synthetic crystals of monosodium urate. A Scanning electron micrograph of synthetic MSU crystals $(\times 50,000)$. B MSU crystals under polarized light $(\times 400)$. C MSU crystals from the synovial fluid of a gout patient $(\times 400)$. The white bar indicates the axis compensator. (DOCX $1750 \mathrm{~kb}$ )

Additional file 3: Characterization of synoviocytes derived from five primary cultures from different patients. A Typical morphology of fibroblasts. B Expression of $\mathrm{PDH} 4+$ in synoviocytes by IFA, expression of intracellularly localized PDH4+ by confocal microscopy. C Protein expression of PDH4+ by WB. (DOCX $840 \mathrm{~kb}$ )

Additional file 4: UGDH gene expression and CD14 in synoviocytes. Synoviocytes characterized by qRT-PCR. Each bar shows the average \pm standard deviation of three independent experiments from different patients $(n=5) ;{ }^{*} P<0.05$. (DOCX $\left.25 \mathrm{~kb}\right)$

Additional file 5: Characterization of cell populations. Synoviocytes culture marked with anti-CD166 and anti-CD14. Each bar shows the average \pm standard deviation of three independent experiments from different patients $(n=5) ;{ }^{*} P<0.05$. (DOCX $26 \mathrm{~kb}$ )

\section{Abbreviations}

DNPH: 2, 4-dinitrophenylhydrazine; FC: flow cytometry; FLS: fibroblast-like synoviocytes; IL: interleukin; MP: misfolded glycoproteins aggregates; MSU: monosodium urate; NLRP3: NACHT, LRR and PYD domain-containing protein 3; NO: nitric oxide; OS: oxidative stress; RE: rough endoplasmic reticulum; RNS: nitrogen species; ROS: reactive oxygen species; SEM: scanning electron microscopy; SM: synovial membrane; TNF: tumor necrosis factor; UA: uric acid; WB: western blot.

\section{Competing interests}

The authors declare that they have no competing interests.

\section{Authors' contributions}

YZC and ALR designed the study coordination, were responsible for integrity of the work, interpretation of data, and drafting the manuscript, and gave final approval to the version of the paper to be published. CHD, JCG, and MG collected and interpreted data from patients and clinics samples, drafted the manuscript, and helped to revise it. KMF and YALB performed the protein analysis by western blot, interpretation of data, and drafting the manuscript. MGSO and JFT performed the quantitative real-time PCR and analyzed the data for the draft of the manuscript. ALM and DML performed the experiments with cell stimulation, interpretation of data and helped to revise the manuscript. EOLV and JFCC performed the electron microscopy analysis, interpreted the results, and were involved in drafting the manuscript. FO and AS participated in the interpretation of the data, drafted the manuscript and performed the statistical analysis. CP designed the study, drafted and revised the paper, and gave final approval of the final version manuscript. All authors read and approved the final version of the manuscript.

\section{Acknowledgements}

We thank Carlos Landa Solís, MSc, for flow cytometry support, and Alma Delia Hernández Pérez, BS, of Pathology Services at the Instituto Nacional de Rehabilitacion for the micrographs obtained for this study. There was no funding for this study.

\section{Author details}

'Laboratorio de Líquido Sinovial, Instituto Nacional de Rehabilitación "Luis Guillermo Ibarra Ibarra", Calzada México-Xochimilco 289, Tlalpan, 14389 Mexico City, Mexico. ${ }^{2}$ Laboratorio de Microbiología Molecular, Departamento de Microbiología, Escuela Nacional de Ciencias Biológicas (ENCB), Instituto Politécnico Nacional (IPN), Prolongación de Carpio y Plan de Ayala S/N Col. Casco de Santo Tomas, Miguel Hidalgo, 11340 Mexico City, Mexico. ${ }^{3}$ Biological and Health Sciences PhD program, Universidad Autónoma Metropolitana, Avenida San Rafael Atlixco 186, Iztapalapa, 09340 Mexico City, Mexico. ${ }^{4}$ Laboratorio Central de Microscopía, Departamento de Investigación, ENCB, IPN, Prolongación de Carpio y Plan de Ayala S/N Col. Santo Tomás, Miguel Hidalgo, 11340 Mexico City, Mexico. ${ }^{5}$ Rheumatology Unit, Department of Medicine-DIMED, University of Padova, Via Giustiniani, 2, Padova 35128, Italy.

Received: 31 January 2016 Accepted: 3 May 2016

Published online: 21 May 2016

\section{References}

1. Choi HK, Niu J, Neogi T, Chen CA, Chaisson C, Hunter D, et al. Nocturnal risk of gout attacks. Arthritis Rheumatol. 2015;67:555-562. doi:10.1002/art.38917.

2. García-Méndez S, Arreguín-Reyes R, López-López O, Vázquez MJ. Frecuencia de la gota según la percepción de los médicos en México. Reumatol Clin. 2014;10:197-8. 
3. Cronstein BN, Terkeltaub R. The inflammatory process of gout and its treatment. Arthritis Res Ther. 2006;8 Suppl 1:S3.

4. Martinon F, Petrilli V, Mayor A, Tardivel A, Tschoop J. Gout associated uric acid crystals activate the NALP3 inflammasome. Nature. 2006;440:237-41.

5. Stamp LK, Turner R, Khalilova IS, Zhang M, Drake J, Forbes LV, et al. Myeloperoxidase and oxidation of uric acid in gout: implications for the clinical consequences of hyperuricaemia. Rheumatology (Oxford). 2014; 53:1958-65.

6. Kim SK, Choe JY, Park KY. Rebamipide suppresses monosodium urate crystal-induced interleukin-1 $\beta$ production through regulation of oxidative stress and caspase-1 in THP-1 cells. Inflammation. 2016;39:473-82.

7. Pouliot M, James MJ, McColl SR, Naccache PH, Cleland LG. Monosodium urate microcrystals induce cyclooxygenase-2 in human monocytes. Blood. 2012;91:1769-76.

8. So A, Thorens B. Uric acid transport and disease. Sci Med J Clin Invest. 2010;120:1791-9.

9. Zheng SC, Zhu XX, Xue Y, Zhang LH, Zou HJ, Qiu JH, et al. Role of the NLRP3 inflammasome in the transient release of IL-1 $\beta$ induced by monosodium urate crystals in human fibroblast-like synoviocytes. J Inflamm (Lond). 2015;12:30. doi:10.1186/s12950-015-0070-7.

10. Scanu A, Oliviero F, Gruaz L, Sfriso P, Pozzuoli A, Frezzato F, et al. Highdensity lipoproteins downregulate CCL2 production in human fibroblast-like synoviocytes stimulated by urate crystals. Arthritis Res Ther. 2010;2:R12. http://arthritis-research.com/content/12/1/R23.

11. Trevisan G, Hoffmeister C, Rossato MF, Oliveira SM, Silva MA, Silva CR, et al. TRPA1 receptor stimulation by hydrogen peroxide is critical to trigger hyperalgesia and inflammation in a model of acute gout. Free Radic Biol Med. 2014;72:200-9. doi:10.1016/j.freeradbiomed.2014.04.021.

12. Denko CW, Whitehouse MW. Experimental inflammation induced by natural occurring microcrystalline calcium salts. J Rheumatol. 1976;3:54-62.

13. Paul H, Reginato AJ, Schumacher HR. Morphological characteristics of monosodium urate: transmission electron microscopic study of intact natural and synthetic crystals. Ann Rheum Dis. 1983;42:75-81.

14. Chomczynski P, Sacchi N. Single-step method of RNA isolation by acid guanidinium thiocyanate-phenol-chloroform extraction. Anal Biochem. 1987;162:156-9.

15. Serratos IN, Castellanos P, Pastor N, Millán-Pacheco C, Rembao D, PérezMontfort R, et al. Modeling the Interaction between quinolinate and the receptor for advanced glycation end products (RAGE): relevance for early neuropathological processes. PLoS One. 2015;10(3):e0120221. doi:10.1371/ journal.pone.0120221.

16. Landa-Solís C, Granados-Montiel J, Olivos-Meza A, Ortega-Sánchez C, CruzLemini M, Hernández-Flores C, et al. Cryopreserved CD90+ cells obtained from mobilized peripheral blood in sheep: a new source of mesenchymal stem cells for preclinical applications. Cell Tissue Bank. 2016;17(1):137-45. doi:10.1007/s10561-015-9526-5.

17. Flick DA, Gifford G. Comparison of in vitro cell cytotoxic assays for tumor necrosis factor. J Immunol Methods. 1984;68:167-75.

18. Zamudio-Cuevas Y, Díaz-Sobac R, Vázquez-Luna A, Landa-Solís C, Cruz-Ramos M, Santamaría-Olmedo M, et al. The antioxidant activity of soursop decreases the expression of a member of the NADPH oxidase family. Food Funct. 2014;5(2):3039. doi:10.1039/c3fo60135h.

19. Stankovíc A, Front P, Barbara A, Mitrovíc DR. Tophus-derived monosodium urate monohydrate crystals are biologically much more active than synthetic counterpart. Rheumatol Int. 1991;10:221-6.

20. Tudan C, Jackson JK, Blanis L, Pelech SL, Burt HM. Inhibition of TNF-alpha-induced neutrophil apoptosis by crystals of calcium pyrophosphate dihydrate is mediated by the extracellular signal-regulated kinase and phosphatidylinositol 3-kinase/Akt pathways up-stream of caspase 3 . J Immunol. 2000;165:5798-806.

21. Chhana A, Callon KE, Pool B, Naot D, Watson M, Gamble GD, et al. Monosodium urate monohydrate crystals inhibit osteoblast viability and function: implications for development of bone erosion in gout. Ann Rheum Dis. 2011:70:1684-91.

22. Choe JY, Park KY, Kim SK. Oxidative stress by monosodium urate crystals promotes renal cell apoptosis through mitochondrial caspase-dependent pathway in human embryonic kidney 293 cells: mechanism for urate-induced nephropathy. Apoptosis. 2015;20:38-49.

23. Malemud CJ, Sun Y, Pearlman E, Ginley NM, Awadallah A, Wisler BA, et al. Monosodium urate and tumor necrosis factor-a increase apoptosis in human chondrocyte cultures. Rheumatology (Sunnyvale). 2012;2:113.
24. David-Raoudi M, Deschrevel B, Leclercq S, Galéra P, Boumediene K, Pujol JP. Chondroitin sulfate increases hyaluronan production by human synoviocytes through differential regulation of hyaluronan synthases: Role of p38 and Akt. Arthritis Rheum. 2009;60:760-70.

25. Cillero-Pastor B, Martin MA, Arenas J, López-Armada MJ, Blanco FJ. Effect of nitric oxide on mitochondrial activity of human synovial cells. BMC Musculoskelet Dis. 2011;12:42. doi:10.1186/1471-2474-12-42.

26. Van't Hof RJ, Hocking L, Wright PK, Ralston SH. Nitric oxide is a mediator of apoptosis in the rheumatoid joint. Rheumatology (Oxford). 2000;39:1004-8.

27. Jhang JJ, Cheng YT, Ho CY, Yen GC. Monosodium urate crystals trigger Nrf2and heme oxygenase-1-dependent inflammation in THP-1 cells. Cell Mol Immunol. 2015;12:424-34.

28. Chenevier-Gobeaux C, Lemarechal H, Bonnefont-Rousselot D, Poiraudeau S, Ekindjian OG, Borderie D. Superoxide production and NADPH oxidase expression in human rheumatoid synovial cells: regulation by interleukin1 beta and tumor necrosis factor-alpha. Inflamm Res. 2006;55:483-90.

29. Zheng S, Zhong ZM, Qin S, Chen GX, Wu Q, Zeng JH, et al. Advanced oxidation protein products induce inflammatory response in fibroblast like synoviocytes through NADPH oxidase dependent activation of NF-KB. Cell Physiol Biochem. 2013;32:972-85.

30. Fedorova M, Kuleva N, Hoffmann R. Reversible and irreversible modifications of skeletal muscle proteins in a rat model of acute oxidative stress. Biochim Biophys Acta. 2009;1792(12):1185-93. doi:10.1016/j.bbadis.2009.09.011.

31. Dalle-Donne I, Rossi R, Giustarini D, Milzania A, Colombo R. Protein carbonyl groups as biomarkers of oxidative stress. 2003. Clin Chim Acta. 2003; 329:23-38.

32. Merry P, Winyard PG, Morris CJ, Grootveld M, Blake DR. Oxygen free radicals, inflammation, and synovitis: and synovitis: the current status. Ann Rheum Dis. 1989:48:864-70

33. Dai M, Wei W, Shen YX, Zheng YQ. Glucosides of Chaenomeles speciose remit rat adjuvant arthritis by inhibiting synoviocyte activities. Acta Pharmacol Sin. 2003;24:1161-6.

34. Butoescu N, Seemayer CA, Foti M, Jordan O, Doelker E. Dexamethasonecontaining PLGA superparamagnetic microparticles as carriers for the local treatment of arthritis. Biomaterials. 2009:30:1772-80.

35. Shin HY, Oh JM, Kim YS. The functional role of prion protein $\left(\operatorname{PrP}^{\mathrm{C}}\right)$ on autophagy. Pathogens. 2013:2:436-45.

36. Betteridge DJ. What is oxidative stress? Metabolism. 2000;49:3-8.

\section{Submit your next manuscript to BioMed Central and we will help you at every step:}

- We accept pre-submission inquiries

- Our selector tool helps you to find the most relevant journal

- We provide round the clock customer support

- Convenient online submission

- Thorough peer review

- Inclusion in PubMed and all major indexing services

- Maximum visibility for your research

Submit your manuscript at www biomedcentral.com/submit

C) Biomed Central 